\title{
Swelling of organoclays in styrene. Effect on flammability in polystyrene nanocomposites
}

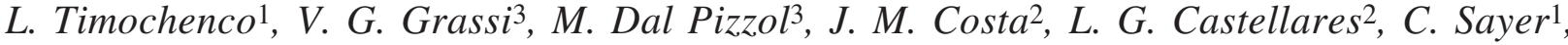 \\ R. A. F. Machado1, P. H. H. Araújo ${ }^{*}$ \\ ${ }^{1}$ Department of Chemical Engineering, Federal University of Santa Catarina, CEP 88040 900, Florianópolis SC, Brazil \\ ${ }^{2}$ CENPES/PETROBRÁS R\&D Center Rio de Janeiro RJ, Brazil \\ ${ }^{3}$ Innova S/A Triunfo RS, Brazil
}

Received 14 January 2010; accepted in revised form 23 March 2010

\begin{abstract}
In this work the effect of the compatibility between organoclays and styrene on the flammability of polystyrene/clay nanocomposites obtained through in situ incorporation was investigated. The reactions were carried out by bulk polymerization. The compatibility between organoclays and styrene was inferred from swelling of the organoclay in styrene. The nanocomposites were characterized by X-ray diffraction and Transmission Electron Microscopy. The heat release rate was obtained by Cone Calorimeter and the nanocomposites were tested by UL94 horizontal burn test. Results showed that intercalated and partially exfoliated polystyrene/clay nanocomposites were obtained depending on the swelling behavior of the organoclay in styrene. The nanocomposites submitted to UL94 burning test presented a burning rate faster than the virgin polystyrene (PS), however an increase of the decomposition temperature and an accentuated decrease on the peak of heat release of the nanocomposites were also observed compared to virgin PS. These results indicate that PS/clay nanocomposites, either intercalated or partially exfoliated, reduced the flammability approximately by the same extent, although reduced the ignition resistance of the PS.
\end{abstract}

Keywords: nanocomposites, flammability, polystyrene, organoclay, swelling

\section{Introduction}

In situ incorporation is an effective route to obtain polystyrene/clay nanocomposites [1-10]. Nonetheless, the compatibility between monomer and organoclay is a critical factor in determining the microstructure of nanocomposites obtained through in situ incorporation [1]. A good compatibility between monomer and organoclay is fundamental to disperse the clay in the reaction medium, avoiding its agglomeration. In addition, the penetration of the monomer into the basal space of lamellae allows the entrance of oligomeric radicals and the consequent intercalation of lamellae with polymer. If the separation of the lamellae is high enough, delamination (exfoliation) occurs.
Liauw et al. [2] had measured the swelling volume and the viscosity of organoclays in toluene considering that the compatibility of organoclays with styrene can be considered in the same way as with toluene and therefore can be a predictor of state of clay dispersion within the resulting composite. Fu and Qutubuddin [1] determined the swelling behavior of organoclays in styrene comparing wettability and rheology measurements and observed that the organoclay prepared with a styryl group had the highest compatibility with styrene and formed exfoliated polystyrene nanocomposites while the organoclays that presented weaker interaction formed intercalated polystyrene nanocomposites after polymerization of styrene and organoclay

*Corresponding author, e-mail: pedro@enq.ufsc.br (C) BME-PT 
mixtures. Similar results were observed by Arioli et al. [3] when comparing the swelling volume of organoclays in styrene. The higher the swelling volume the higher the degree of organoclay exfoliation in polymer matrix after polymerization of styrene in the presence of organoclay. The use of other solvent mixtures (tetrahydrofuran and water) resulted in different clay intercalation with styrenevinylpyridine (SVP, $36.40 \mathrm{wt} \%$ styrene and $63.60 \mathrm{wt} \%$ 4-vinylpyridine) block copolymers in the in situ formation of polystyrene/clay nanocomposite and the most effective exfoliated nanocomposite, showed the highest thermal stability and the best dynamic mechanical responses [11]. The significant enhancement of both tensile and flexural strength in polymer/clay nanocomposites is usually attributed to the delaminated clay formation [12]. The good dispersion of clay produces a substantial improvement in fire performance in polymeric matrices such as polystyrene [10,13-18] at least in terms of peak heat release rate (Peak HRR) accessed by cone calorimeter. The suggested mechanism by which clay nanocomposites reduce the heat release rate involves the formation of a char that serves as a barrier to both mass and energy transport [10]. According to Levchik and Weil [19] flame retardancy achieved with nanocomposites alone is not enough for the ignition resistance inferred by the UL-94 test and they suggest a better approach to combine the nanocomposite with another flame retardant, such that the nanocomposite provides the base reduction in flammability, and the secondary flame retardant provides the ignition resistance. Several papers [20-22] investigated the effect of the chemical and physical structure of polymer/clay interfaces on the flammability of polymer composites and nanocomposites. Some of these papers showed that the clay/polymer nanocomposite improved not only the cone calorimetry results, but the UL94 performance as well. One of the reasons is the increase of viscosity caused by clay that arrests the dripping of the polymer during burning which is reflected by the UL94 rating [21]. The objective of this work is to investigate the correlation of the compatibility between monomer and organoclay and the flammability properties of the polystyrene/clay nanocomposite obtained through in situ incorporation. To attain this objective, different organoclays were incorporated to the polymer matrix through styrene bulk polymerization.
The compatibility between organoclays and styrene was inferred from swelling of the organoclay in styrene. The nanocomposites were characterized and the thermal stability and flammability were studied.

\section{Material and methods}

Styrene was provided by Innova S.A., Brazil, with a purity about $99.6 \%$ and inhibitor (p-terc-butilcatechol) concentration equal to $12 \mathrm{ppm}$. Benzoyl peroxide (BPO) with $75 \%$ of active oxygen P.A. grade (Elf Atochem Chemicals, USA) was used as initiator. The montmorillonite (MMT) containing exchangeable cations of primarily $\mathrm{Na}^{+}$was provided by Southern Clay Products, USA. The organoclays were prepared and supplied by Southern Clay (Cloisite 10A and Cloisite 15A), USA, and by SüdChemie (Nanofil 15), Germany. All reactants, including the clays, were used as received, without any previous treatment. The Cloisite $10 \mathrm{~A}$ and Cloisite 15A clays were the SWy-1 montmorillonite modified by 2MBHT (dimethyl-benzylhydrogenated-tallow, quaternary ammonium) and 2M2HT (dimethyl-dihydrogenatedtallow, quaternary ammonium), respectively. The hydrogenated tallow was a mixture of $\sim 65 \%$ of $\mathrm{C} 18, \sim 30 \%$ of $\mathrm{C} 16$ and $\sim 5 \%$ of $\mathrm{C} 14$ and the anion was the chloride. The Nanofil 15 clay was a montmorillonite modified with $\mathrm{C} 18$ chains (distearyl-dimethyl ammonium chloride).

\subsection{Bulk polymerization}

At first $3.0 \%$ of clay in relation to the total mass of polymer was dispersed in styrene (S) during two hours under vigorous stirring (1200 rpm) in a jacketed reactor at $25^{\circ} \mathrm{C}$. This step was conducted to allow the dispersion and swelling of the clay with the styrene. After this initial dispersion step, the reactor temperature was raised up to $90^{\circ} \mathrm{C}$ and initiator $(0.5 \% \mathrm{w} / \mathrm{w}$ related to the total mass of monomer) was added to the reaction medium. Reaction was kept at $90^{\circ} \mathrm{C}$ for 2 hours after which the reaction medium was transferred to an aluminum vessel and immersed in an oil bath with a gradual temperature increase $\left(20^{\circ} \mathrm{C} /\right.$ hour $)$ up to $180^{\circ} \mathrm{C}$, maintained for 2 additional hours. Nitrogen was fed to the reactor during the whole reaction to avoid inhibition by oxygen. 


\subsection{Characterization}

The swelling volume of organoclays in styrene was measured using a $100 \mathrm{ml}$ measuring cylinder. The sample $(1.0 \mathrm{~g})$ was sprinkled onto the styrene surface $(100 \mathrm{ml})$ and it slowly fell to the bottom of the cylinder. The swelling volume was recorded after $24 \mathrm{~h}$ (a swelling equilibrium was reached by this time). XRD patterns of organoclays and polystyrene nanocomposites were obtained by using Philips X'Pert X-ray diffractometer, with a Cu tube source (wavelength $\lambda$ of $1.54056 \AA$ ) operated at $1 \mathrm{~kW}$. Transmission electron microscopy (TEM) images of polystyrene/layered silicate (clay) nanocomposites were obtained at $100 \mathrm{kV}$, with a JEOL electron microscope. The samples were ultramicrotomed with a diamond knife on a Leica Ultracut UCT microtome at room temperature to give $70 \mathrm{~nm}$ thick sections. The sections were transferred to carbon-coated $\mathrm{Cu}$ grids of 200 mesh. The contrast between the layered silicates and the polymer phase was sufficient for imaging, so no heavy metal staining of sections prior to imaging was required.

Thermogravimetric analyses (TGA) were conducted on a Shimadzu TGA-50 equipment, under inert atmosphere with a $\mathrm{N}_{2}$ flux of $50 \mathrm{ml} / \mathrm{min}$ and heating rate of $10^{\circ} \mathrm{C} / \mathrm{min}$, until the final temperature, $600^{\circ} \mathrm{C}$, was reached. The horizontal burning test UL94 [23] was conducted according to the ASTM D635 procedure [24]. The dimension of the standard bar samples were $125 \times 13 \times 3 \mathrm{~mm}$. The flammability data reported here were the averages of five samples. Combustion behavior was assessed according to the ASTM E 1354 [25] procedure in a Fire Testing Technology (FTT) dual cone calorimeter apparatus. During the test, the materials were subjected to irradiated heat plus the feedback heat from the flame starting from the ignition of the volatile products (ignition time). The aim was to simulate the conditions likely to occur in a real fire [26]. The samples were irradiated at $35 \mathrm{~kW} / \mathrm{m}^{2}$, and the data were collected for the first $250 \mathrm{~s}$, this being regarded as representative of the initial stage of a fire when it can still be stopped before becoming uncontrollable after flashover. The exhaust gas flow rate was $24 \mathrm{l} / \mathrm{s}$. The heat released was calculated from the consumption of oxygen due to combustion. The analysis by cone calorimeter gives the ignition time $\left(T_{i g}\right)$, the heat release rate (HRR) and its peak value (Peak HRR), the average value of heat release rate over the entire heat release rate curve for the material during combustion of the sample (Avg HRR) and the total heat release.

\section{Results and discussion}

Swelling tests were performed in order to characterize the organoclays in respect to their affinity towards styrene. The values of swelling of the three tested clays might be observed in Table 1. According to the results shown in Table 1, two samples (Nanofil 15 and Cloisite 15A) presented moderate swelling values, whereas clay Cloisite $10 \mathrm{~A}$ presented the highest value. The naturally occurring Na-MMT did not swell in styrene. The higher the swelling volume, the higher the compatibility between the organoclay and styrene. All clays tested in this work were montmorillonite modified with quaternary ammonium salts. The salts used to modify the organophilicity of the clays Nanofil 15 and Cloisite 15A presented dimethyl-dehydrogenated-tallows, being the tallow of Cloisite $15 \mathrm{~A}$ a mixture of $\sim 65 \%$ of $\mathrm{C} 18, \sim 30 \%$ of $\mathrm{C} 16$ and $~ 5 \%$ of C14 and the tallow of Nanofil 15 clay was composed by $\mathrm{C} 18$ chains. As the swelling value provides an information about the affinity of the clay towards the monomer, Cloisite 10A presented the higher swelling value as its quaternary ammonium salt was composed by a dimethyl-benzyl-hydrogenated-tallow that presents a high compatibility with styrene as observed before by other authors [1, 2]. Similar results were obtained by $\mathrm{Fu}$ and Qutubuddin [4] that observed that montmorillonite modified with vinylbenzyldodecyldimethyl ammonium chloride gave the highest styrene dispersion viscosity by a wide margin (more than 10 times), when compared to montmorillonite clays modified with quaternary ammonium salts featuring alkyl chains of $\mathrm{C} 16$ to $\mathrm{C} 18$. The high degree of styrene compatibility afforded by the styryl group of the quaternary ammonium salt illustrates the importance of matching monomer/polymer structure to that of the intercalant [2].

Table 1. Swelling volumes of Na-MMT and organoclays in Styrene at $25^{\circ} \mathrm{C}$

\begin{tabular}{|l|c|}
\hline \multicolumn{1}{|c|}{ Clay } & ml clay/100 ml Sty \\
\hline Na-MMT & - \\
\hline Cloisite 10A & 26 \\
\hline Cloisite 15A & 12 \\
\hline Nanofil 15 & 15 \\
\hline
\end{tabular}




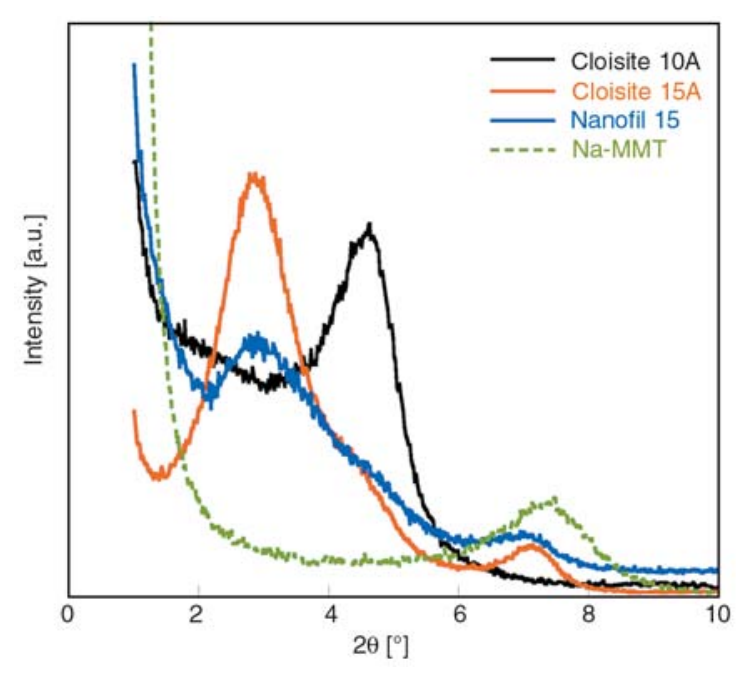

Figure 1. XRD patterns of clays

The interlamellar layer $(d)$ of the clay was measured by X-ray diffraction (XRD). The $d_{001}$ spacing of clay particles was calculated according to Bragg's law where $d=\lambda / 2 \sin (\theta)$ at peak positions. The wave-length $(\lambda)$ of X-ray is $1.5418 \AA$. In Figure 1 it is possible to observe that all organoclays show sharp peaks and the peak positions shift to lower angles when compared to natural occuring montmorillonite (Na-MMT) which contains exchangeable cations of primarily $\mathrm{Na}^{+}$. Nanofil 15 and Cloisite $15 \mathrm{~A}$ presented different diffractograms, although the values of $d_{001}$ spacing (3.03 and $3.07 \mathrm{~nm}$, respectively) were quite similar. The diffractograms of both clays presented a small peak around $1.2 \mathrm{~nm}$ that do not correspond to $d_{002}$ spacing and seems to be quite similar to the crystallographic spacing of Na-MMT $(1.18 \mathrm{~nm})$. This means that both clays could contain small amounts of tactoids with clays platelets intercalated with cations of $\mathrm{Na}^{+}$. Cloisite 10A presented just a single peak corresponding to a $d_{001}$ spacing value of $1.91 \mathrm{~nm}$.

In order to determine the effect of the swelling volume of the clay in the monomer, the styrene dispersions were polymerized in situ. XRD and TEM were used to characterize the dispersions of the organoclays in polystyrene (PS). The in situ incorporation of Na-MMT resulted in a very heterogeneous composite, when the stirring of the reaction medium was stopped the Na-MMT clay sedimented to the bottom of the reaction vessel. No further analysis was performed on this resulting composite. On contrary, the organoclays were very well dispersed in the polystyrene matrix. Figure 2 shows

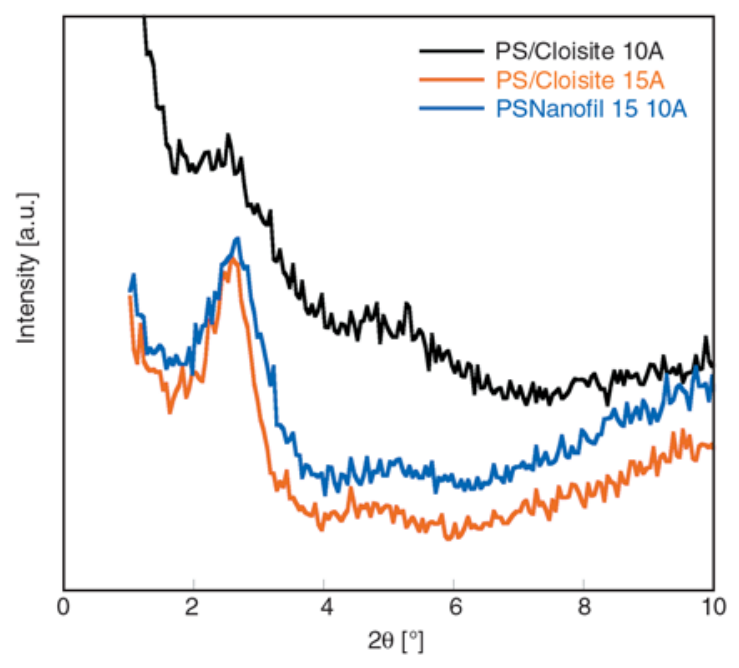

Figure 2. XRD patterns of nanocomposites

the diffractograms of the resulting nanocomposites. No clearly defined peak can be observed in the curve of PS/Cloisite 10A nanocomposite indicating that the clay could be delaminated. The PS/ Cloisite 15A nanocomposite presented the displacement of the peak to $2.58^{\circ}$, corresponding to a basal spacing of $3.42 \mathrm{~nm}$. This means that an increase of the interlayer distance has occurred by PS polymer chains polymerized in the interlayer of clay platelets. A similar diffractogram was observed for PS/ Nanofil 15 nanocomposite with a well defined peak at $2 \theta$ equal to $2.91^{\circ}\left(d_{001}=3.38 \mathrm{~nm}\right)$ These results indicate that both nanocomposites (PS/Cloisite 15A and PS/Nanofil 15) presented an intercalated structure.

TEM micrographs of the nanocomposites show similar dispersion of all clays in polystyrene. The thin dark lines of Figure 3 suggest that some clay layers of the organophilic clays are exfoliated in polystyrene, while other layers have intercalated structure as it is possible to observe MMT stacks dispersed in polymer matrix. TEM and XRD results suggest that the nanocomposite PS/Cloisite 10A was partially exfoliated whereas the nanocomposites PS/Cloisite 15A and PS/Nanofil 15 presented a predominant intercalated structure.

Thermogravimetric analysis: The TGA data of the samples (Figure 4) showed that the polymer nanocomposites, decompose at higher temperatures compared to virgin PS. The temperature at which $5 \%$ degradation occurred, representative of the onset temperature of degradation, and the midpoint degradation temperature, corresponding to the temperature at which the weight loss of the sample 


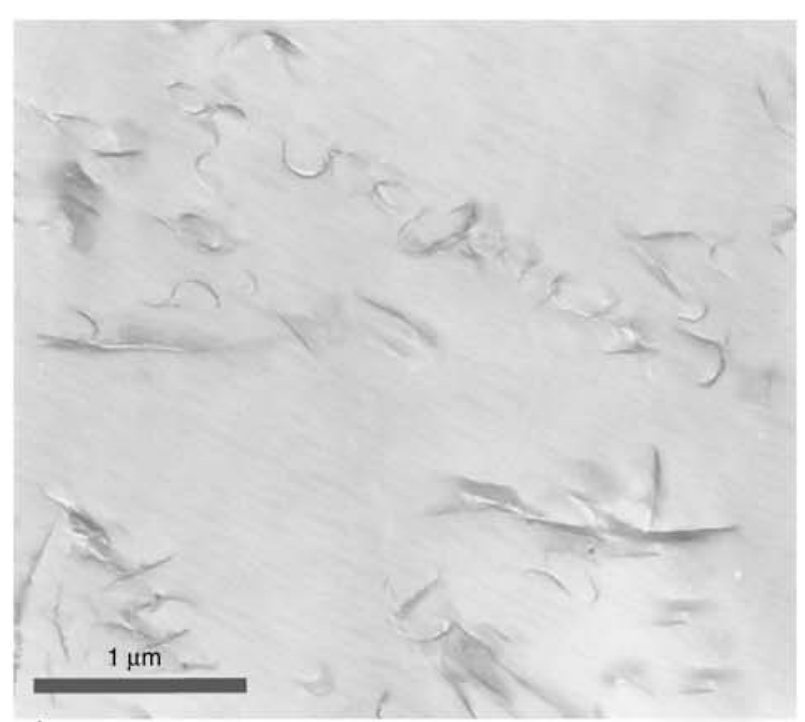

a)

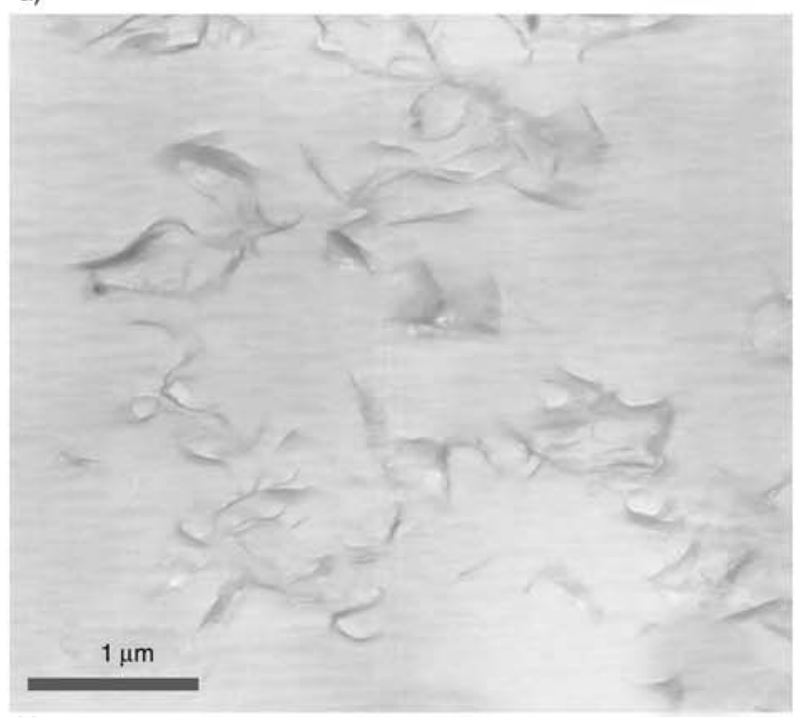

b)

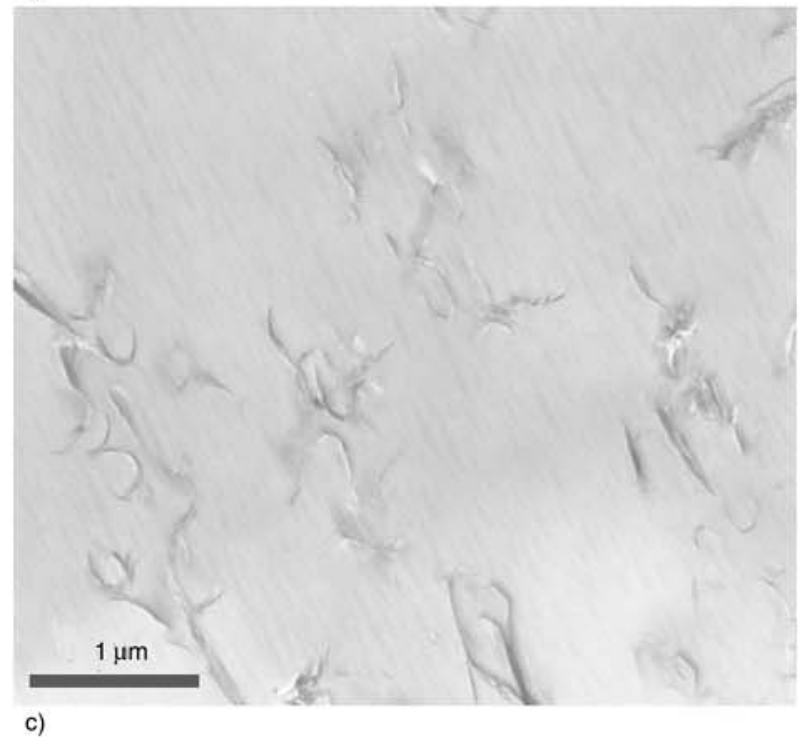

c)

Figure 3. TEM micrographs of the nanocomposites: PS/Cloisite 10A (a), PS/Cloisite 15A (b) and PS/Nanofil 15 (c)

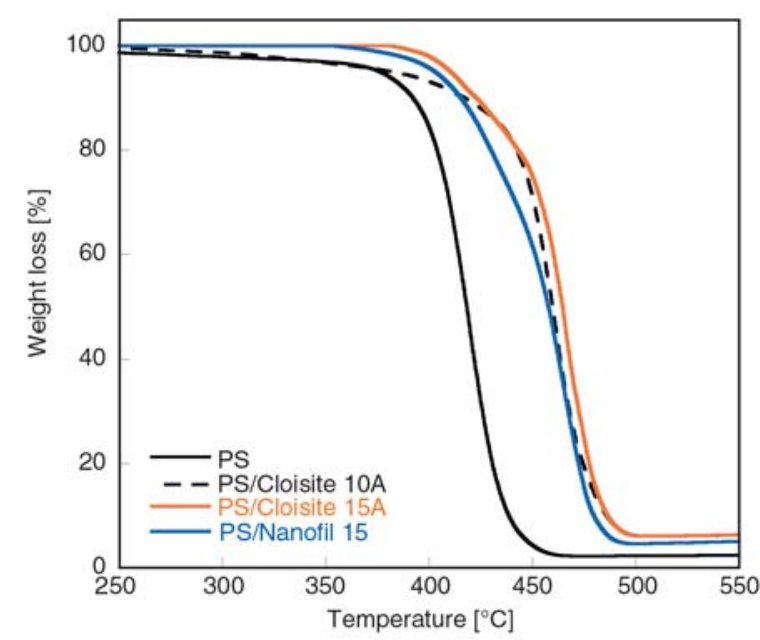

Figure 4. TGA of virgin polystyrene (PS) and of PS/clay nanocomposites

attains 50\%, were found to be highest for PS/ Cloisite $15 \mathrm{~A}$ ( 410.6 and $464.5^{\circ} \mathrm{C}$, respectively). The higher degradation temperatures may probably be attributed to extensive interaction of PS with nanodispersed and large surface area organophilic clays that resulted in inhibition of the diffusion of the decomposed product in the polymer matrix. Although all nanocomposites (PS/Cloisite 10A, PS/Cloisite 15A and PS/Nanofil 15) had high midpoint degradation temperatures $(459.8,464.5$ and $457.6^{\circ} \mathrm{C}$, respectively), when compared to virgin PS $\left(418.1^{\circ} \mathrm{C}\right)$, nanocomposite PS/Cloisite $10 \mathrm{~A}$ lost initial $5 \%$ weight at a temperature $\left(382.2^{\circ} \mathrm{C}\right)$ just $5.8^{\circ} \mathrm{C}$ higher than virgin PS $\left(376.4^{\circ} \mathrm{C}\right)$.

UL94 test: The results of the flammability analysis assessed by UL94 horizontal burning test are presented in Table 2. These results show that the burning rate was faster for the nanocomposites than for the virgin polystyrene. Similar result was previously reported by other authors that credit the poor UL94 performance of the clay/polymer composite to the presence of the compatibilizers present in the organoclays. These compatibilizers are added to the clay in order to increase the affinity of the clay for the monomer. As UL94 burning test should be regarded primarily as an ignition test and since the

Table 2. Burning rate (UL94)

\begin{tabular}{|l|c|}
\hline \multicolumn{1}{|c|}{ Sample } & Burning rate $[\mathbf{m m} / \mathbf{m i n}]$ \\
\hline PS & 12.9 \\
\hline PS/Cloisite 10A & 21.2 \\
\hline PS/Cloisite 15A & 27.1 \\
\hline PS/Nanofil 15 & 16.7 \\
\hline
\end{tabular}


organoclays shorten the ignition time they can degrade UL94 performance [27, 28]. Nevertheless, a very different behavior was observed during the burning of virgin PS and PS/organoclay nanocomposites, as during the burning of PS/organoclay nanocomposites, a char structure was formed and no dripping was observed, whereas during the burning of virgin PS specimen dripping of melted polystyrene in flame was constant.

Cone calorimeter: The heat release rates (HRRs) of the virgin polymer (PS) and the nanocomposite (PS/organoclay) during the combustion tests are shown in Figure 5. When the organoclays are present, the ignition time $\left(T_{i g}\right)$ decreases from 66 to 52-59 s (see Table 3). Just after ignition, however, the virgin polystyrene heat release rate (HRR) increases much more quickly. The heat release rate of the PS overtakes that of the nanocomposite after $60 \mathrm{~s}$ of $T_{i g}\left(\mathrm{HRR}=600 \mathrm{~kW} / \mathrm{m}^{2}\right)$, peaks at $1303 \mathrm{~kW} / \mathrm{m}^{2}$ after $202 \mathrm{~s}$ of $T_{i g}$, and then falls very sharply after $240 \mathrm{~s}$ of $T_{i g}$. The heat release rate of the composite rises regularly to a maximum of $663-704 \mathrm{~kW} / \mathrm{m}^{2}$ after $171-178 \mathrm{~s}$ of Tig. Reduction of the peak heat release rate is a typical feature of polymer layered silicate nanocomposites, as reported in the literature [14-18]. The combustion behavior of the nanocomposite is due to a reduction in the mass loss rate, compared to that of the poly-

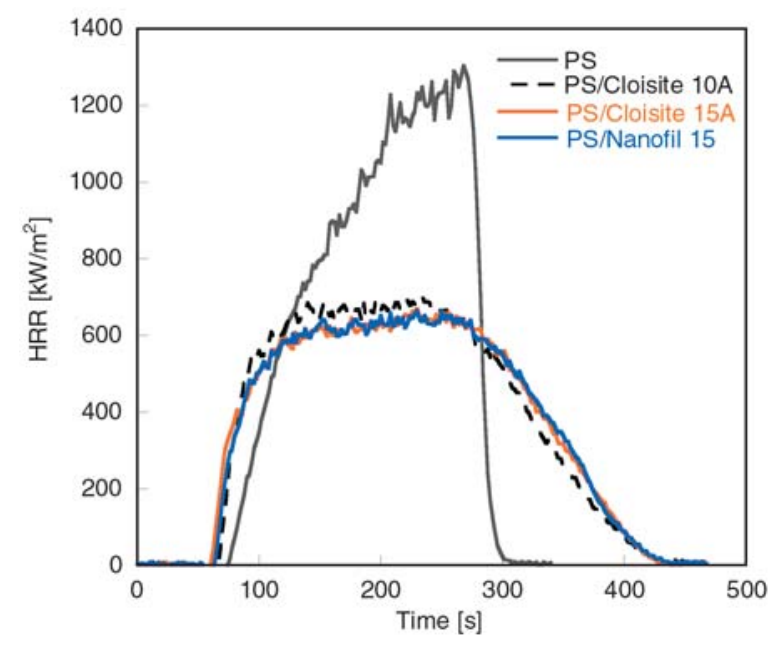

Figure 5. HRR of virgin polystyrene (PS) and of PS/clay nanocomposites mer. This greater thermal stability stems from the chemical and physical action of the crystalline layers of the silicate dispersed in the matrix that inhibited the diffusion of the decomposed product in the polymer matrix. Thermal decomposition of the organically modified montmorillonites starts at around $200^{\circ} \mathrm{C}$ and proceeds according to the Hofmann degradation mechanism [19]. The decomposition products are combustibles that feed the combustion in the flame. Despite a larger heat release rate in the early stage of combustion, the nanocomposite shows an improvement of fire behavior compared to those of the virgin polymer (Table 3). The average heat release rate (Avg. HRR) decreases from $807 \mathrm{~kW} / \mathrm{m}^{2}$ (virgin PS) to $448-475 \mathrm{~kW} / \mathrm{m}^{2}$ (PS/organoclay).

During the cone calorimeter analysis it was observed that once the virgin PS specimen ignited the sample surface did begin to boil rapidly as the polymer burned away, but the flames were steady (not turbulent) as the material burned. After burning no significant char was noted, just some soot and ash in the aluminum sample pan. Whereas for the nanocomposites, once sample ignited the flames were steady and no boiling of polymer underneath the flame front was noted. Formation of condensed phase char was noticeable during the entire burning process. The final char was black and highly cracked, with the aluminum foil clearly seen underneath (see Figure 6). The fire behavior of the nanocomposite PS/Nanofil 15 was identical to that of the others nanocomposites but the char was more pronounced and could be seen sticking up in the flame front area as the sample burned. Char formation is good for fire retardancy purposes as the char prevents the entry of flammable gases into the gas phase and insulates the underlying polymer from the flame [29].

Char formation in cone experiments corroborates the observations during UL94 tests, where a char structure formed during burning was observed for the nanocomposites but not for the virgin PS. The apparently contradictory results of cone calorimeter and UL94 horizontal burning test regarding the

Table 3. Results of the cone calorimeter analysis

\begin{tabular}{|l|c|c|c|c|}
\hline \multicolumn{1}{|c|}{ Sample } & Time to ignition [s] & Time to peak [s] & Peak HRR [kW/m²] & Avg. HRR [kW/m²] \\
\hline PS & 66 & 202 & 1303 & 807 \\
\hline PS/Cloisite 10A & 59 & 171 & 704 & 475 \\
\hline PS/Cloisite 15A & 52 & 178 & 669 & 461 \\
\hline PS/Nanofil 15 & 55 & 175 & 663 & 448 \\
\hline
\end{tabular}




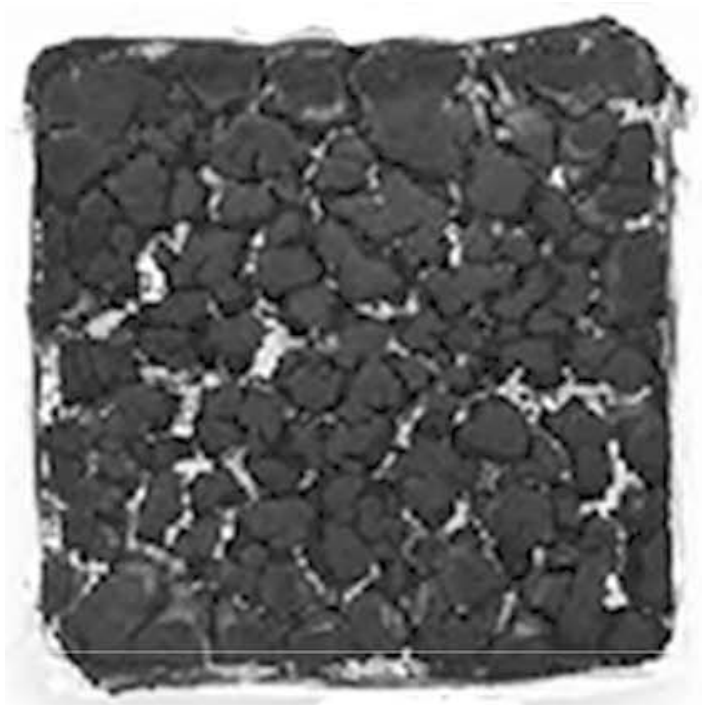

a)

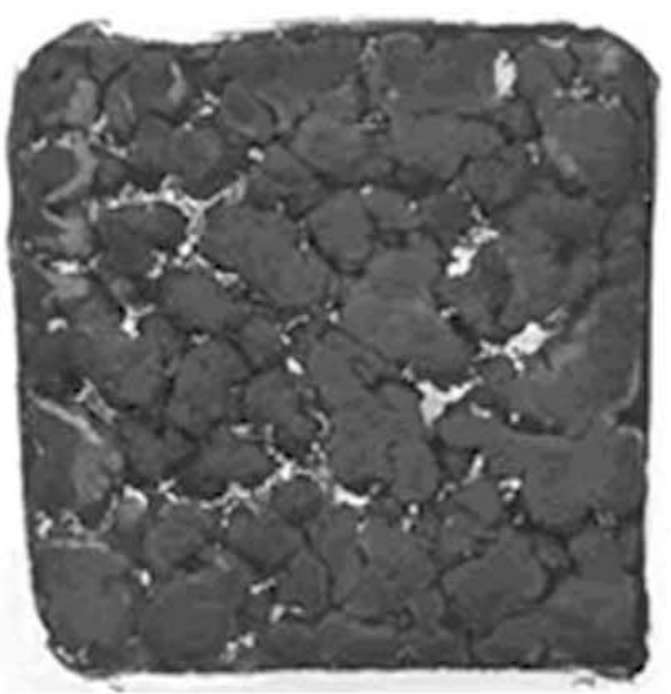

b)

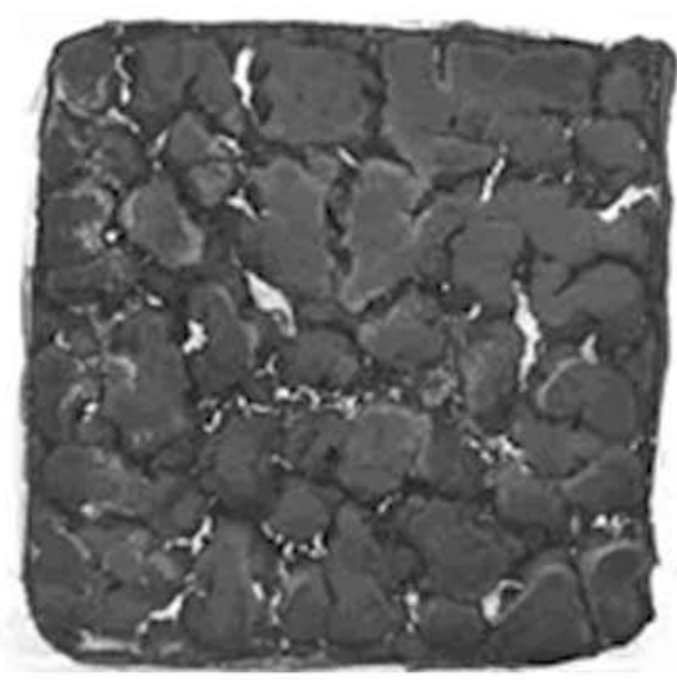

c)

Figure 6. Pictures of the residues of nanocomposites after the cone experiment. a) PS/Cloisite 10A, b) PS/Cloisite $15 \mathrm{~A}, \mathrm{c}$ ) PS/Nanofil 15 (pictures size of $75 \times 75 \mathrm{~mm})$ flammability of the nanocomposites could be explained because UL94 is primarily an ignition test. The thermal degradation of the excess of quaternary ammonium surfactants used to disperse the clays form flammable volatile vapors increasing the probability of early ignition, this behavior was observed in the reduced time to ignition measured by cone calorimeter.

Results indicate that intercalated and partially exfoliated polystyrene/clay nanocomposites presented similar flammability properties assessed by cone calorimeter analysis. These results are in accordance with a recent work of Samyn et al. [30] where it was observed that polyamide-6/organoclay nanocomposites exhibit significant reduction of Peak HRR but the nanomorphology (exfoliation, intercalation and presence of tactoids) did not play any significant role. It means that if the nanodispersion is achieved, the polymer/organoclay nanocomposite should exhibit flame retardancy properties, at least in terms of Peak HRR.

\section{Conclusions}

Results showed that intercalated and partially exfoliated polystyrene/clay nanocomposites were obtained depending on the swelling behavior of the organoclay in styrene. UL94 burning test showed that the burning rate was faster for the nanocomposites than for the virgin polystyrene and that during the burning of PS/organoclay nanocomposites, a char structure was formed and no dripping was observed, whereas during the burning of virgin PS specimen dripping of melted polystyrene in flame was constant.

It was also observed an increase of the higher decomposition temperature and an accentuated decrease on the peak of heat release of the nanocomposites when comparing to the virgin polymer. These results indicate that polystyrene/clay nanocomposite, either intercalated or partially exfoliated, reduced the flammability approximately at the same extent, although reduced the ignition resistance of the polystyrene. 


\section{Acknowledgements}

The authors thank the financial support from $\mathrm{CNPq}-\mathrm{Con}-$ selho Nacional de Desenvolvimento Científico e Tecnológico, MCT/FNDCT/FINEP (Açoes Transversais: Nanocompósitos, 0.1.05.0547.00) and PETROBRÁS / CENPES (PD-01644).

\section{References}

[1] Fu X., Qutubuddin S.: Swelling behavior of organoclays in styrene and exfoliation in nanocomposites. Journal of Colloid Interface Science, 283, 373-379 (2005).

DOI: $10.1016 /$ j.jcis.2004.09.037

[2] Liauw C. M., Lees G. C., Rothon R. N., Wilkinson A. N., Limpanapittayatorn P.: Evaluation of an alternative modification route for layered silicates and synthesis of poly(styrene) layered silicate nanocomposites by in-situ suspension polymerisation. Composites Interfaces, 14, 361-386 (2007). DOI: $10.1163 / 156855407780452896$

[3] Arioli R., Gonçalves O. H., Castellares L. G., Costa J. M., Araújo P. H. H., Machado R. A. F., Bolzan A.: Effect of foster swelling degree in polystyrene/clay nanocomposites obtained by in situ incorporation. Macromolecular Symposia, 245-246, 337-342 (2006). DOI: $10.1002 /$ masy.200651346

[4] Fu X., Qutubuddin S.: Polymer-clay nanocomposites: Exfoliation of organophilic montmorillonite nanolayers in polystyrene. Polymer, 42, 807-813 (2001). DOI: $10.1016 / \mathrm{S} 0032-3861(00) 00385-2$

[5] Fu X., Qutubuddin S.: Synthesis of polystyrene-clay nanocomposites. Materials Letters, 42, 12-15 (2000). DOI: 10.1016/S0167-577X(99)00151-2

[6] Doh J. G., Cho I.: Synthesis and properties of polystyrene-organoammonium montmorillonite hybrid. Polymer Bulletin, 41, 511-518 (1998).

DOI: $10.1007 / \mathrm{s} 002890050395$

[7] Okamoto M., Morita S., Taguchi H., Kim Y. H., Kotaka T., Tateyama H.: Synthesis and structure of smectic clay/poly(methyl methacrylate) and clay/ polystyrene nanocomposites via in situ intercalative polymerization. Polymer, 41, 3887-3890 (2000). DOI: 10.1016/S0032-3861(99)00655-2

[8] Weimer M. W., Chen H., Giannelis E. P., Sogah D. Y.: Direct synthesis of dispersed nanocomposites by in situ living free radical polymerization using a silicate-anchored initiator. Journal of the American Chemical Society, 121, 1615-1616 (1999). DOI: $10.1021 / \mathrm{ja} 983751 \mathrm{y}$

[9] Bottcher H., Hallensleben M. L., Nu S., Wurm H., Bauerb J., Behrens P.: Organic/inorganic hybrids by living/controlled ATRP grafting from layered silicates. Journal of Materials Chemistry, 12, 1351-1354 (2002).

DOI: $\underline{10.1039 / \mathrm{b} 110819 \mathrm{k}}$
[10] Zhu J., Morgan A. B., Lamelas F. J., Wilkie C. A.: Fire properties of polystyrene-clay nanocomposites. Chemistry of Materials, 13, 3774-3780 (2001). DOI: $10.1021 / \mathrm{cm} 000984 \mathrm{r}$

[11] Sen S., Nugay N., Nugay T.: Effects of the nature and combinations of solvents in the intercalation of clay with block copolymers on the properties of polymer nanocomposites. Journal of Applied Polymer Science, 112, 52-63 (2009). DOI: 10.1002/app.29389

[12] Chow W. S., Mohd Ishak Z. A.: Mechanical, morphological and rheological properties of polyamide 6/ organo-montmorillonite nanocomposites. Express Polymer Letters, 1, 77-83 (2007). DOI: $10.3144 /$ expresspolymlett.2007.14

[13] Sanchez-Olivares G., Sanchez-Solis A., Camino G., Manero O.: Study on the combustion behavior of high impact polystyrene nanocomposites produced by different extrusion processes. Express Polymer Letters, 2, 569-578 (2008). DOI: $\underline{10.3144 / \text { expresspolymlett.2008.69 }}$

[14] Gilman J. W., Jackson C. L., Morgan A. B., Harris R., Manias E., Giannelis E. P., Wuthenow M., Hilton D., Phillips S. H.: Flammability properties of polymerlayered-silicate nanocomposites. Polypropylene and polystyrene nanocomposites. Chemistry of Materials, 12, 1866-1873 (2000).

DOI: $10.1021 / \mathrm{cm} 0001760$

[15] Bourbigot S., Vanderhart D. L., Gilman J. W., Bellayer S., Stretz H., Paul D. R.: Solid state NMR characterization and flammability of styrene-acrylonitrile copolymer montmorillonite nanocomposite. Polymer, 45, 7627-7638 (2004).

DOI: $10.1016 /$ j.polymer.2004.08.057

[16] Morgan A. B., Chu L-L., Harris J. D.: A flammability performance comparison between synthetic and natural clays in polystyrene nanocomposites. Fire and Materials, 29, 213-229 (2005).

DOI: $10.1002 /$ fam.881

[17] Bourbigot S., Gilman J. W., Wilkie C. A.: Kinetic analysis of the thermal degradation of polystyrenemontmorillonite nanocomposite. Polymer Degradation and Stability, 84, 483-492 (2004). DOI: $\underline{10.1016 / j . p o l y m d e g r a d s t a b .2004 .01 .006}$

[18] Zheng X., Jiang D. D., Wang D., Wilkie C. A.: Flammability of styrenic polymer clay nanocomposites based on a methyl methacrylate oligomerically-modified clay. Polymer Degradation and Stability, 91, 289297 (2006).

DOI: $10.1016 /$ j.polymdegradstab.2005.05.007

[19] Levchik S. V., Weil E. D.: New developments in flame retardancy of styrene thermoplastics and foams. Polymer International, 57, 431-448 (2008). DOI: $10.1002 /$ pi. 2282 
[20] Marosi G., Anna P., Márton A., Bertalan G., Bóta A., Tóth A., Mohai M., Rácz I.: Flame-retarded polyolefin systems of controlled interphase. Polymers for Advanced Technologies, 13, 1103-1111 (2002). DOI: $10.1002 /$ pat.284

[21] Marosi G., Márton A., Szép A., Csontos I., Keszei S., Zimonyi E., Tóth A., Almeras X.: Fire retardancy effect of migration in polypropylene nanocomposites induced by modified interlayer. Polymer Degradation and Stability, 82, 379-385 (2003). DOI: $\underline{10.1016 / \mathrm{S} 0141-3910(03) 00223-4}$

[22] Keszei S., Matkó Sz., Bertalan G., Anna P., Marosi G., Tóth A.: Progress in interface modifications: From compatibilization to adaptive and smart interphases. European Polymer Journal, 41, 697-705 (2005). DOI: $10.1016 /$ j.eurpolymj.2004.10.039

[23] UL-94: Test for flammability of plastic materials for parts in devices and appliances (2006).

[24] ASTM D635: Standard test method for rate of burning and/or extent and time of burning of plastics in a horizontal position (2006).

[25] ASTM E1354: Standard test method for heat and visible smoke release rates for materials and products using an oxygen consumption calorimeter (2004).
[26] Zanetti M., Camino G., Canavese D., Morgan A. B., Lamelas F. J., Wilkie C. A.: Fire retardant halogenantimony-clay synergism in polypropylene layered silicate nanocomposites. Chemistry of Materials, 14, 189-193 (2002).

DOI: $10.1021 / \mathrm{cm} 011124 \mathrm{t}$

[27] Si M., Zaitsev V., Goldman M., Frenkel A., Peiffer D. G., Weil E. D., Sokolov J. C., Rafailovich M. H.: Selfextinguishing polymer/organoclay nanocomposites. Polymer Degradation and Stability, 92, 86-93 (2007). DOI: $10.1016 /$ j.polymdegradstab.2006.08.023

[28] Morgan A. B., Bundy M.: Cone calorimeter analysis of UL-94 V-rated plastics. Fire and Materials, 31, 257-283 (2007).

DOI: $\underline{10.1002 / \text { fam. } 937}$

[29] Manzi-Nshuti C., Hossenlopp J. M., Wilkie C. A.: Comparative study on the flammability of polyethylene modified with commercial fire retardants and a zinc aluminum oleate layered double hydroxide. Polymer Degradation and Stability, 94, 782-788 (2009). DOI: $10.1016 /$ j.polymdegradstab.2009.02.004

[30] Samyn F., Bourbigot S., Jama C., Bellayer S.: Fire retardancy of polymer clay nanocomposites: Is there an influence of the nanomorphology? Polymer Degradation and Stability, 93, 2019-2024 (2008). DOI: $10.1016 /$ j.polymdegradstab.2008.02.013 